\title{
Access Control System: A Smart Home Solution
}

\author{
Nermin Hamza * \\ Faculty of computing and \\ information technology \\ King Abdul Aziz University \\ B.P. 42808 Zip Code 21551 \\ Girl Section, Jeddah, KSA \\ * Institute of Statistical Studies \\ and Research, Cairo University \\ Cairo, Egypt
}

\author{
Amjad Khalid Al-Harthi \\ Faculty of computing and \\ information technology \\ King Abdul Aziz University \\ B.P. 42808 Zip Code 21551 \\ Girl Section, Jeddah, KSA
}

\author{
Maram Hassan Al-Safri \\ Faculty of computing and \\ information technology \\ King Abdul Aziz University \\ B.P. 42808 Zip Code 21551 \\ Girl Section, Jeddah, KSA
}

\begin{abstract}
Nowadays, the technological applications have the widest range in our daily life, for instance, automation systems, robotics, and smart home. Smart home is an automated system developed to achieve some actions performed frequently in daily life to obtain more comfortable and easier life environment. Elderly and People has special needs can get benefit from smart home technologies. They can use their mobile to allow their assistance to do many services. In this paper, we proposed a smart home solution based on remote controlling in the house door called Smart Access Control.

The solution allowed to the authorized people to enter their home using their mobiles or just if registered in the system. In addition, it monitors who tries to access the home at any time. The proposed work uses integrated technologies such as face recognition and embedded system together to handle the access permission and the user can administer it remotely by using a mobile application.
\end{abstract}

Keywords- IOT; smart home; (Raspberry Pi); embedded system and Face recognition

\section{INTRODUCTION}

Internet of Things (IoT) is a concept and a paradigm that uses the variety of things/objects/ Devices through wireless and wired connections and unique addressing schemes are able to interact with each other and cooperate with other things/objects to create new applications/services and reach common goals. [1]. People are becoming busier and loaded. IOT try to make all home services smarts, and Hardware devices can do their job remotely.

The smart home is technology features that improve quality of life, monitor activities of their peoples. It is a cost-effective way of improving home care. Smart homes are equipped with sensors, and/or monitors. These devices operate in a network connected to a remote center for data collection and processing. [ 2].

In this proposed work we try to introduce solution help the life to be more easy and smart. The home accessing one of the main Jobs we do every day. People may forget their keys or forget to lock their homes and many security issues are related to who want to access the home.

Our contribution is to propose a solution to enable the homeowners to do many Jobs related to the home Door using their mobile Application called smart access control system. The solution utilizes the face recognition system to identify the authorized people face in order to allow them to access their home like young people or home owners who forget their keys. In addition, it includes a mobile application to let the owner control the access of his building remotely in case of older people cannot able to go and open the door. We apply this solution at Jeddah, KSA.

The paper is organized as follows: The next section gives an overview of Internet of Things and smart home creation and concept. The third section presents the alternative solutions in access control. Section four explains the proposed system, component and architecture. Section five presents the solution description. the discussion will be in section six. it's used Technologies at section seven.

\section{IOT OVERVIEW}

British technology pioneer Kevin Ashton who the first person used the term "Internet of Things" (IoT) at the early of this century. He described a system in which objects in the physical world could be connected to the Internet by sensors [3]. Internet of Things (IoT) is a concept and a paradigm that considers pervasive presence in the environment of a variety of things/objects that through wireless and wired connections and unique addressing schemes are able to interact with each other and cooperate with other things/objects to create new applications/services and reach common goals. [4] IOT could be wide network of interconnected objects that are unique addressable based on the standard communication protocols. The Internet of Things is based on the fact that the interoperability of the solutions for both the communication and the services must be provided on various platforms. [5];

IoT describes a system where items in the physical world, and sensors within or attached to these items, are connected to the Internet via wireless and wired Internet connections. [6] In IOT the data can be small in size and frequent in transmission. The number of devices, or nodes, that are connecting to the network are also greater in IoT than in traditional PC computing. A S Abdul-Qawy at 2015 [5] determine the key elements of IOT as the following: a) Identification and Addressing, b) Embedded sensors, c) Protocols and Middle ware, d) cloud-based storage and analytic e) Applications and f) Core Hardware. IOT could be used indifferent issues for example: Human like Devices attached or Human Body, Home; at Building where people live, it could be Vehicle as System inside moving Vehicle and finally may be Factories as standard production issue. Marsan 
at [3] lists Four IOT models: a) Device-to-Device Communications, b) Device-to-Cloud Communications, c) Device-to-Gateway Model and d) Back-End Data-Sharing Model [3].

Homes of the 21 st century will become more and more selfcontrolled and automated due to the comfort it provides, especially when employed in a private home. One of the greatest opportunities still lies ahead in the form of the "smart home". a smart home is understood as an integration system, which takes advantage of a range of techniques such as computers, network communication as well as produced wiring to connect all indoor subsystems that attach to home appliances and household electrical devices as a whole. [7].

Many existing, well-established home automation systems are based on wired communication. This does not pose a problem until the system is planned well in advance and installed during the physical construction of the building. But Wireless systems can be of great help for automation systems with the advancement of wireless technologies such as $\mathrm{Wi}-\mathrm{Fi}$, cloud networks in the recent past, wireless systems are used every day and everywhere [8]. IOT for smart Homes is the solution.

\section{PREVIOUS WORK}

There are several systems has been published which designed to control the access and few of them are almost similar to our proposed system. In the following sections, we will evaluate some of the related works.

\subsection{August Smart Lock}

The August Smart Lock was funded by angels and designed by Swiss designer Yves Behar. Users can control and manage the lock with an iOS, Android, or web app. [9],

This system uses smart phone. The limitation of the August Smart Lock is: it is Only available in CA and US, in case of a smartphone out of charge or not have Wi-Fi so, the product doesn't work properly. when owner proximity of the door then its open automatically via smart phone location.

\subsection{Danalock Bluetooth Low Energy Smart Lock}

The Danalock outperforms other smart locks by offering both Bluetooth and Z-Wave technologies. Through use, it will automatically unlock the door for the user. [10] This system used also smart phone. In This System People using smartphone to lock or unlock your door.in addition, an owner can share others limited or unlimited access keys for home.

The limitation of this solution is: Opening the door using smartphone via Bluetooth Smart technology.

\section{THE PROPOSED WORK}

First, we start by analysis phase by defining the process of collecting the accurate data, understanding the involved processes, identifying challenges, and recommend logical suggestions to enhance the system functionality in the basis of the system requirements. We gathered the data from questionnaire in order to find the user requirements and create a user profile.
We asked the main questions about gender, old, education etc. in addition we asked about phone platform, concerning about mobile phone service, home dependency of other to open home etc. About 1064 persons response our questionnaire. Table 1 discuss in brief the questions and the statistical answers.

Table 1 Presents Sample of the statistical questionnaires

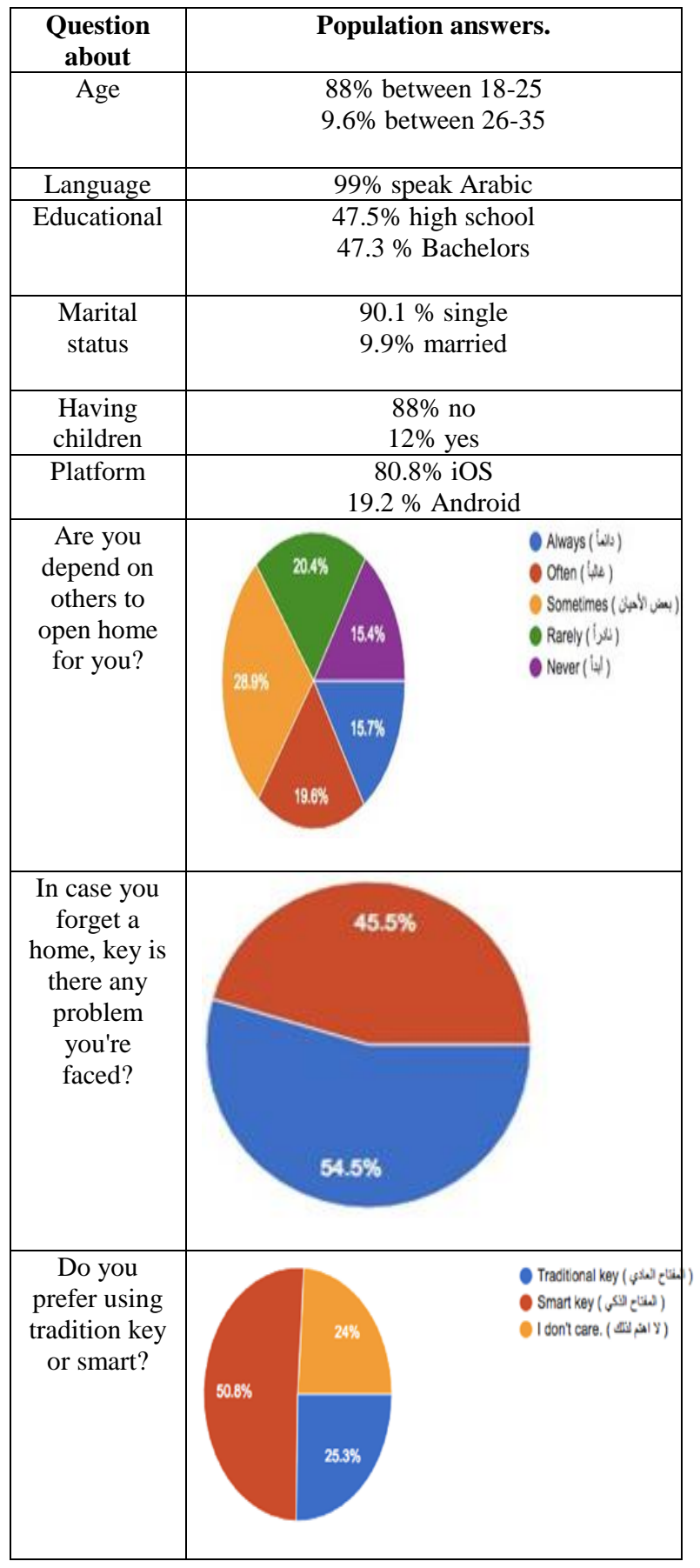




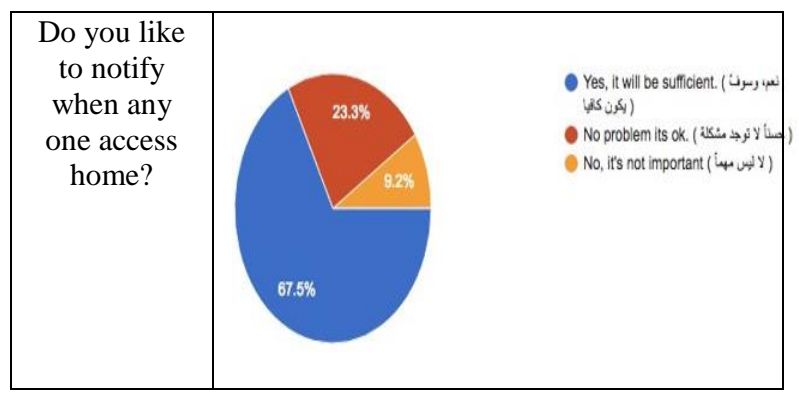

We designed the solution based on 3 main components: 1 . User (application), 2. Web Server and database engine and 3. The Smart Devices included embedded system. Figure 1 illustrate the system components. This part will discuss the 3 main components as following:

\section{A. User and Application}

The End use who has the Application on his/ her mobile. the user is the owner of the building who the only authorized person and who get the permission to enter or refuse also, who can add person to authorized list manually.

\section{B. Database Server}

Which is ta Database Engine server connected to both the Application of End user and the Smart Device. The Database store the face pattern for the authorized persons.

\section{Smart Device}

The smart device is Hardware Device connected with a smart Device include data SIM card to connect with the WIFI, the hardware device is a web camera (high definition) used to capture the face of the guests; the camera is connected with a microcontroller called Raspberry Pi.

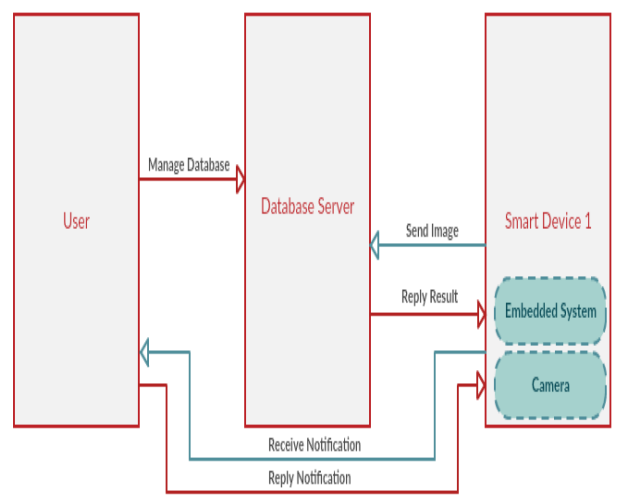

Figure1: (SAC) System components

A use case diagram is the simplest representation of a user's interaction with the system that shows the relationship between the user and the different use cases in which the user is involved. Figure 2 illustrate the use case diagram which has 3 actors and many function requirements.

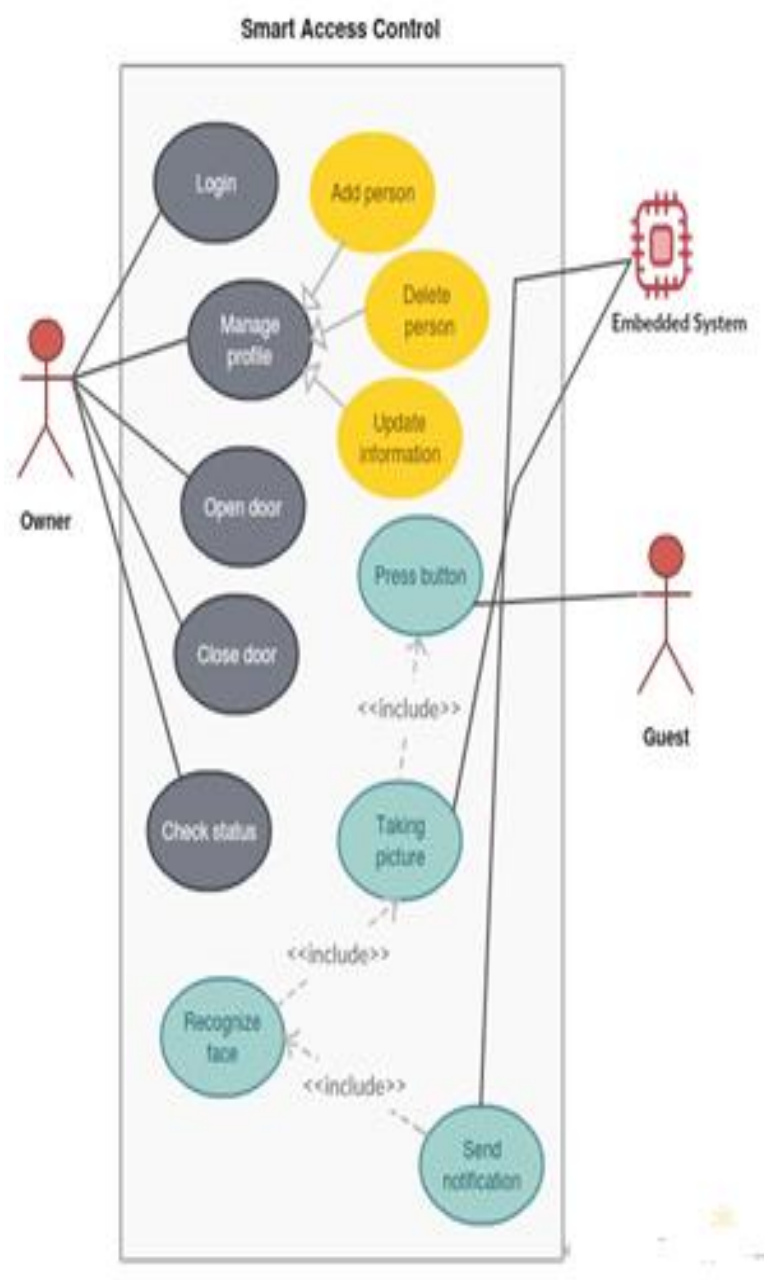

Figure 2 Use Case Diagram

All use cases in Figure 2 designed. Every use case was described in details. For example: Use case name: Send notification allows the owner to know if there anyone arrive to his/her house. Figure 3 discuss "Send Notification use case".

\section{SOLUTION DESCRIPTION}

The user first register to build his own database on the database server. And inserts authorized people to program and stores it in the database. The device also registered to the same account. Then embedded system interacts with the access trials. 


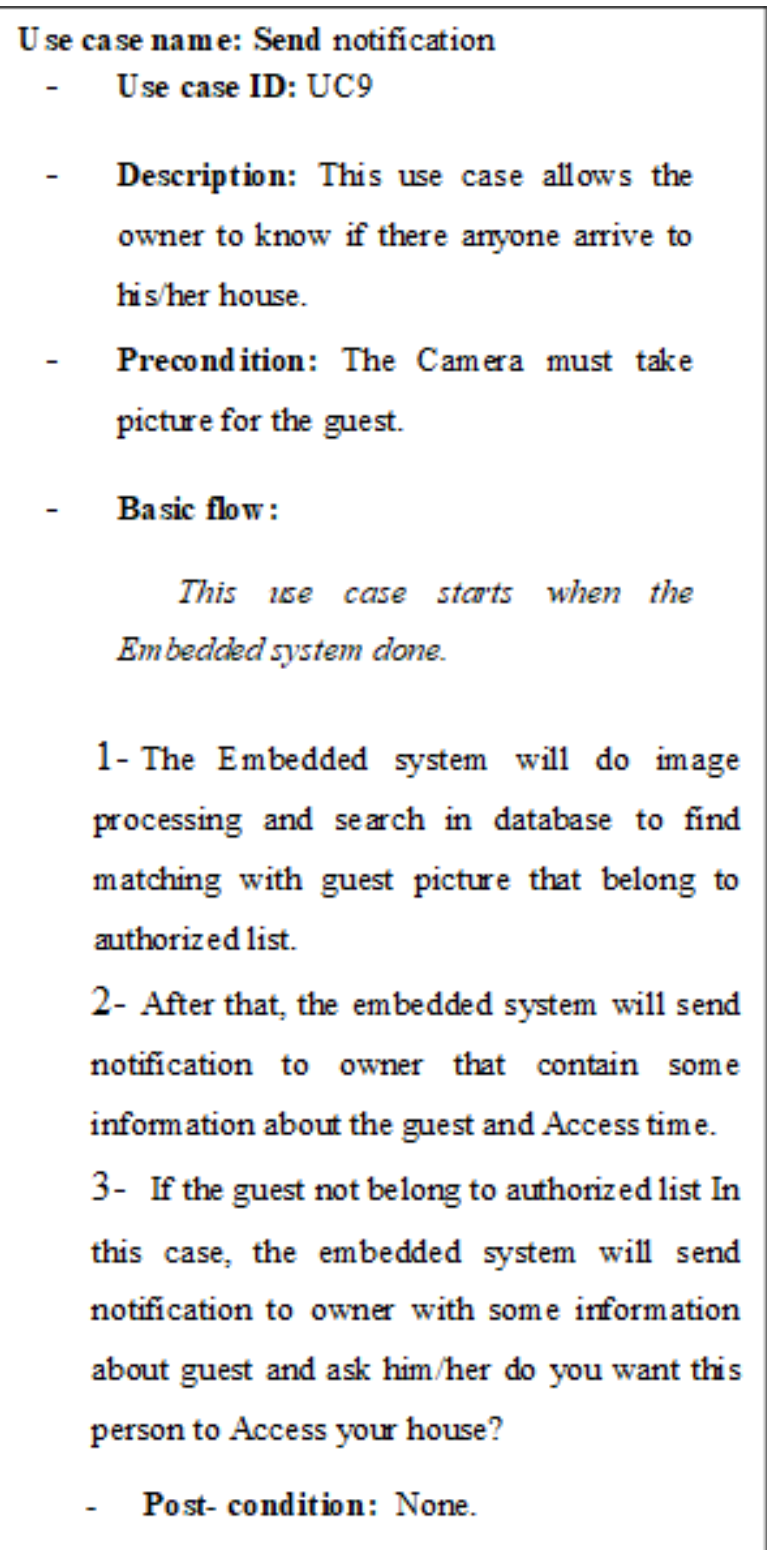

Figure 3: Discuss Send Notification use case.

The door will be opened in two scenarios, the guest is either in the authorized list or the owner allow to the door to be opened via the mobile application. Figure 4 explain the solution flow.

- In case of any unknown guest click the door, what happen?

The guest presses push button to send a signal to embedded system. The embedded system will start working by turning on the camera to take a picture of the guest. The server will send notification to the owner; included guest picture to for asking him/her what to do? The owner is the only who can decide to allow the door to be opened or not.

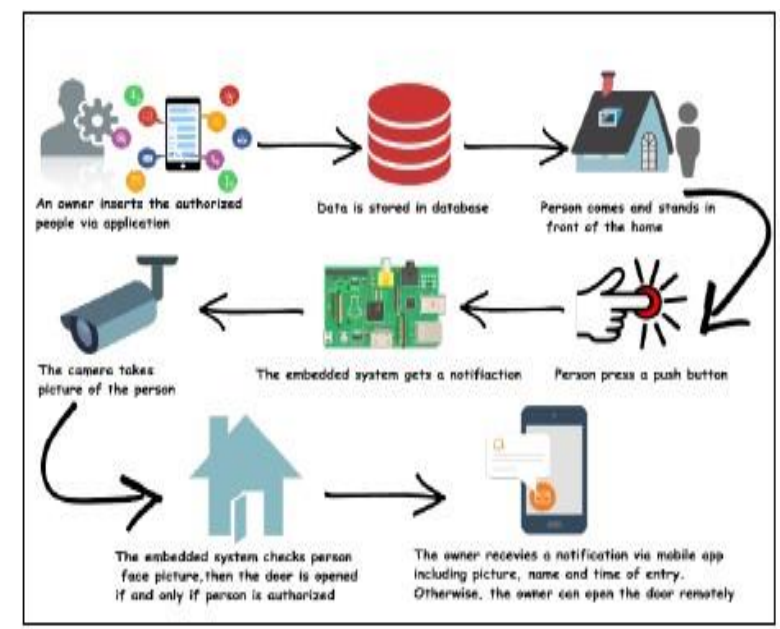

Figure 4 The SAC Description

In our solution we produced services to the owner, and services to the guest. As the following:

\section{A. Owner Services}

- The owner can open/ close the door remotely

- If the owner can allow or refuse opening the door for other. Figure 5 illustrate the owner services.

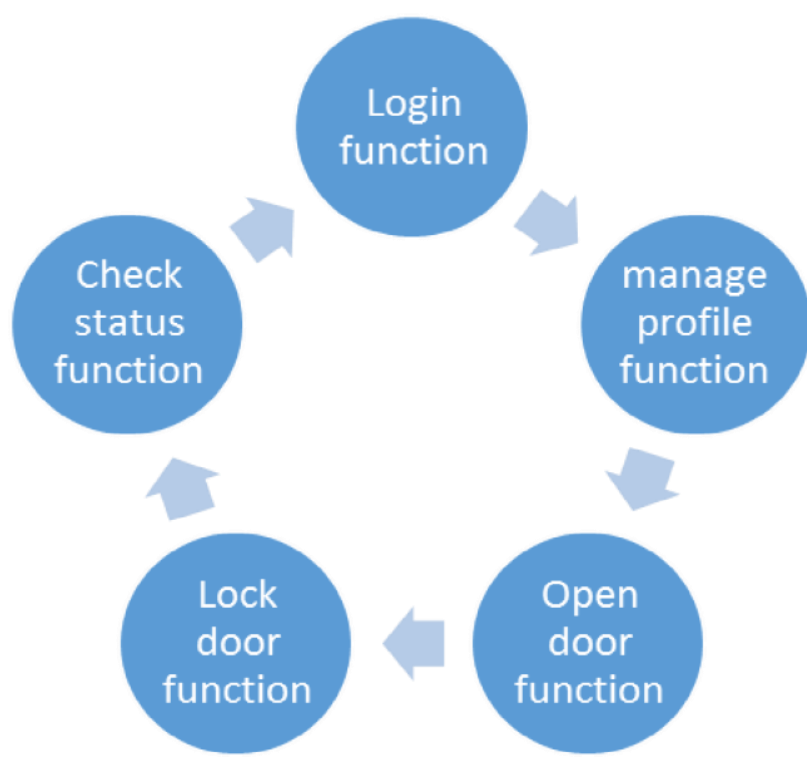

Figure 5: owner services

B. Guest services

- The solution enables Younger people to enter their home in case no one there, open the door for who want to help the older people they cannot service their selves.

- If any stranger tries to enter the home the solution send notification to the owner, how only could decide to allow for them to enter or not. 


\section{INTEGRATED TECHNOLOGIES}

The main two technologies we used Face Recognition and Raspberry Pi. Face recognition is a biometric-based Technique that can recognize individuals throw their digital image by analyzing and comparing patterns. The main applications can apply face recognition systems are commonly security purposes and face Identity. [11].

[There exist several techniques for extracting the useful features from (preprocessed) face images to perform face recognition. We select Local Binary Pattern (LBP) method. This approach was introduced in 1996. With LBP divide the image into several small regions from which the features are extracted. These features consist of binary patterns that describe the surroundings of pixels in the regions. According to several studies face recognition using the LBP method provides very good results. [12]

The other technology is The Raspberry Pi, which is a credit card-sized computer that plugs into your TV and a keyboard. It is a capable little computer which can be used in electronics applications, and for many of the things that your desktop PC does, like spreadsheets, word processing, browsing the internet, and playing games. It also plays highdefinition video. [13]. The Raspberry $\mathrm{Pi}$ is a dynamic microcontroller that is capable of doing just about anything a computer does. It runs with the Python programming language. [14] With Raspberry Pi can doing applications for example:

Smart Home Automation, Robots 'ROV and UAV Camera Streamers, Remote Monitor and supercomputers.

We used more than one tools to implement the proposed solution. First, we build the solution for Android systems so we select one of the android Development tool which is the official Integrated Development Environment (IDE) for Android app development, based on IntelliJ IDEA. Second, we need web server contains the database we select MAMP. MAMP installs a local server environment in a matter of seconds on your computer. It comes free of charge, and is easily installed. MAMP will not compromise any existing Apache installation already running on your system. You can install Apache, PHP and MySQL without starting a script or having to change any configuration files! Furthermore, if MAMP is no longer needed, just delete the MAMP folder and everything returns to its original state (i.e. MAMP does not modify any of the "normal" system). [15,16]. IDLE (Integrated Development Environment or Integrated Development and Learning Environment) another tool we used. IDLE is an integrated development environment for Python, which has been bundled with the default implementation of the language.

Because of using Face recognition Technique, a webcam was needed. A webcam is a video camera that feeds or streams its image in real time to or through a computer to a computer network. When "captured" by the computer, the video stream may be saved, viewed or sent on to other networks via systems such as the internet, and emailed as an attachment.

\section{DISCUSSION}

www.ijcat.com
Smart Access Control (SAC) is a smart home solution helps the owner to control his home using the mobile application. The owner can open or lock his door without need to use his key. Figure 6 illustrates screenshots of SAC solution.

The owner can open the door remotely for his children or trusted persons. If the owner is old or has an elder person inside the home or people have special needs, the owner can use the solution for them.

In addition, the system gives a Security service, as we mentioned, if the guest is authorized person; it could be the owner himself/ herself or any one of the family list; the door will open. Else the guest may be anyone not allowed to enter or unknown persons or may be a thief, the system will not allow entering and send notification to the owner.

An important feature or service in our solution, we used face recognition where smartphone was out of charge, so the server can recognize the authorized persons and give signal to embedded system for opening the door without the need to take agreement from the user.

Smart Access control (SAC) presents many services in the internet of things environment, but it has little limitations associated with the implementation of the solution and it will be our future work. These limitations could be in the camera position; it must be in a fixed position, high resolution and had spot light; also, the quality of the capturing the face might affect the system performance in terms of recognizing faces properly.
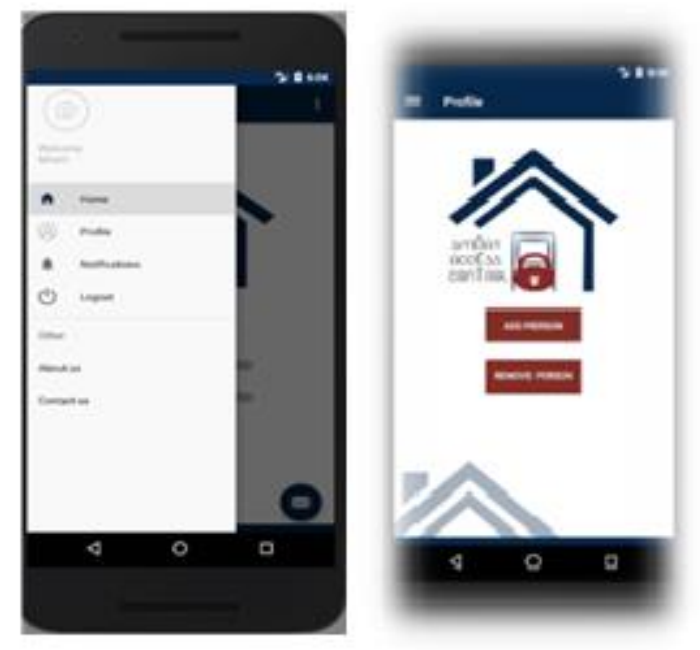

Figure 6 screens of SAC solution

\section{CONCLUSION}

Smart Home is one of IOT technologies. The IOT widely used to solve many problems and help to improve the home services. This paper proposed smart solution to control the home accessibility. The solution based on integrated technologies such as face recognition and embedded system (Raspberry Pi) to control the hardware device; which is a strong and reliable embedded system device in the complex and challenging tasks. Using these technologies in our proposed system to handle the access permission and the user can administer it remotely by using a mobile application. 
The mobile application is connected to a camera in front of the building's entrance and it can communicate with the owner via the application. Furthermore, the holder can send and receive a request to/from the smart access system such as opening the door, show the picture of whom wish to enter the place and create access list for authorized people depending on their facial image.

The face recognition is used in the proposed solution to give permission to open the door for some people who are existed in the authorized list. An important feature in our solution, we used face recognition where smartphone was out of charge, so the server can recognize the authorized persons and give signal to embedded system for opening the door without need to take agreement from the user.

By using this solution, we believe that it may provide an assistance for a better safety and security, life consistent support, offering interactive and efficiency, saving time and effort.

\section{REFERENCES}

[1]. Ovidiu, V. and Peter, F. 2013. Internet of Things: Converging Technologies for Smart Environments and Integrated Ecosystems. River Publishers, ISBN: 978-8792982-96-4

[2]. Blanson, H. Olivier, A., Alpay, Laurence, L., and Dumay Adrie, C.M. 2010. Aging in Place: Self-Care in Smart Home Environments, Smart Home Systems, INTECH Open Access Publisher, pp. 105-120, (February 2010).

[3]. Karen, R., Scott, E. and Lyman, C. 2015. internet of things : an overview understanding the issues and challenges of a more connecting world, The Internet Society (ISOC).

[4]. LOPEZ. R. 2013. An Introduction of internet of things, LOPEZ-Research.

[5]. Antar, S. A., Pramod P. J., E. M. and T. S. The Internet of Things (IoT): An Overvsiew. 2015. Int. Journal of Engineering Research and Applications ISSN:2248-9622, Vol. 5, Issue 12, (Part - 2)(December 2015), pp.71-82

[6]. Nicoleta-Cristina, G.,2, Vasile Gheorghita, G. and Ioan, U. A Survey on the Internet of Things Software Arhitecture. 2015. (IJACSA) International Journal of Advanced Computer Science and Applications, Vol. 6, No. 12

[7]. Jin, C. and Thomas, K. A Survey on Smart Home Networking. 2009 , Carleton University, Systems and Computer Engineering, Technical Report SCE-09-10, ( September 2009)

[8]. Vinay, sagar .K N. and Kusuma, S. M. Home Automation Using Internet of Things.2015, International Research Journal of Engineering and Technology (IRJET) eISSN: 2395 -0056 Volume: 02 Issue: 03 (June-2015)

[9]. August Smart Lock. August Smart Lock | August. 2016. August.

[10].Patrick, S. Comparing the Danalock vs August Smart Lock - All Home Robotics. 2016 All Home Robotics. Retrieved from: http://www.allhomerobotics.com
[11].Divyarajsinh,, N. P. and Brijesh, B. M. Face Recognition Methods \& Applications. 2013 Divyarajsinh N Parmar et al ,Int.J.Computer Technology \& Applications,Vol 4 (1),84-86

[12]. Abdur Rahim, Najmul, H. Tanzillah, W. and Shafiu,l A. Face Recognition using Local Binary Patterns (LBP). 2013 . Global Journal of Computer Science and Technology Graphics \& Vision Volume 13 Issue 4 Version 1.0

[13].Nikhil, P. , Samuel, K. and Manoj, B.Raspberry Pi Augmentation: A cost effective solution to Google Glass. 2017 . International Research Journal of Engineering and Technology (IRJET) Volume: 04 Issue: 03 (Mar -2017)

[14].CAS,. The Raspberry Pi Education Manual. 2012. Computing at School (CAS) Version 1.0 (December 2012)

[15].MAMP . MAMP 3 - User Guide. March 2014 (c) appsolute $\mathrm{GmbH}$

[16].MAMP . MAMP PRO 3 - User Guide. March 2014 (c) appsolute $\mathrm{GmbH}$ 